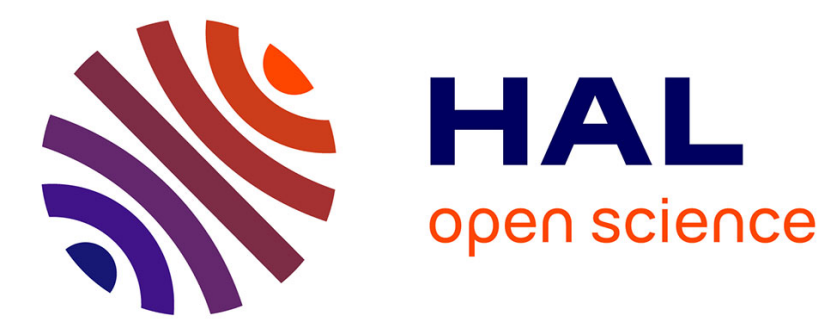

\title{
Decision making in enterprise risk management: A review and introduction to special issue
}

Desheng Wu, David L. Olson, Alexandre Dolgui

\section{To cite this version:}

Desheng $\mathrm{Wu}$, David L. Olson, Alexandre Dolgui. Decision making in enterprise risk management: A review and introduction to special issue. Omega, 2015, 57 (Part A), pp.1-4. 10.1016/j.omega.2015.04.011 . emse-01148657

\section{HAL Id: emse-01148657 \\ https://hal-emse.ccsd.cnrs.fr/emse-01148657}

Submitted on 29 Nov 2021

HAL is a multi-disciplinary open access archive for the deposit and dissemination of scientific research documents, whether they are published or not. The documents may come from teaching and research institutions in France or abroad, or from public or private research centers.
L'archive ouverte pluridisciplinaire HAL, est destinée au dépôt et à la diffusion de documents scientifiques de niveau recherche, publiés ou non, émanant des établissements d'enseignement et de recherche français ou étrangers, des laboratoires publics ou privés. 
Cite this article as: Desheng Wu, David L. Olson, Alexandre Dolgui, Decision making in enterprise risk management: A review and introduction to special issue, Omega, Volume 57, Part A, December 2015, Pages 1-4, http://dx.doi.org/10.1016/j.omega.2015.04.011

\title{
Decision Making in Enterprise Risk Management: a Review and Introduction to Special Issue
}

Desheng $\mathrm{Wu}^{*}$, Management School of University of Chinese Academy of Sciences, Beijing, 100864, China and Stockholm Business School, Stockholm University, Stockholm, Sweden, dash.wu@gmail.com,

David L. Olson*, University of Nebraska, USA, dolson3@unl.edu

Alexandre Dolgui, Ecole des Mines de Nantes, France, alexander.dolgui@mines-nantes.fr

\begin{abstract}
:
Risk-based decision making has been always important in everyday business life. Enterprise risk management (ERM) is the state-of-the-art approach to manage risks facing an organization from system perspective. This paper provides a review of popular literature in ERM using management science approaches, and an introduction of the special issue.
\end{abstract}

Keywords: enterprise risk management, supply chain, financial risk

\section{Introduction}

We all realize that risks are endemic in practically every aspect of our lives. Risks arise from many sources, some natural (the Asian tsunami of 2004; Hurricane Katrina in 2005; the Icelandic volcanic disruption in 2010; the Japanese tsunami of 2011), some malicious caused by humans (the 1995 Sarin attack of a Japanese subway; the 9/11/2001 destruction of the World Trade Center in New York and attack on the Pentagon in Washington, D.C.; bombings of subways in Madrid in 2004, London in 2005, and Moscow in 2010), some due to interaction between human activity and nature (SARS, H1N1, Ebola outbreaks). Humans create complex systems that yield unexpected consequences [1]. Wu and Olson [2] highlighted three events directly involving risk management. One was natural, the 2010 BP oil spill in the Gulf of Mexico. The Enron financial fiasco was only one of a number of cases where business fraud adversely impacted the U.S. economy. The 2008 real estate meltdown had an even greater impact. In 2010, BP suffered an oil spill in the Gulf of Mexico that created problems for the oil business and shipping in the Gulf. We continue to live in a world with unexpected challenges threatening the global business community. 
Enterprise risk management (ERM) is an integrated approach to manage risks facing an organization, seeking the most effective ways to cope with risks. It has become a vital topic in both academia and in practice during the past several decades. ERM received widespread attention following Enron and other corporate scandals, and has emerged as a new discipline. ERM is an integrated approach to manage risks facing organizations that seek the most effective means to deal with these risks.

This paper will review some use of management science in risk management, to include focus on the fields of finance and supply chain management. We will then look at the modeling perspectives of analytic models to include optimization, simulation, and the more focused applications of data mining and multiple criteria analysis. We will conclude with a review of papers in this special issue.

\section{Management Science Tools in Risk Management}

Many different types of models have been proposed to support risk management within organizations [3]. The traditional approach is to develop an analytic model with the intent of identifying an optimal policy [4]. Recently, Choi et al. employ data in both Scopus and ISI Web of Science to identify pioneer management science work in ERM [5]. Because of the uncertainty involved, statistical analysis and simulation is very appropriate to analyze risk. Bayesian analysis has been proposed to model information and knowledge integration within complex networks. Liu et al. provided a hierarchical Bayesian method for identification of defaulters in credit scoring [5]. Simulation was proposed in a number of studies, to include discrete-event simulation to estimate survival in financial risk management [6]. Wu and Olson used Monte Carlo simulation to evaluate risks associated with vendor selection, following up on similar modeling from many sources [7]. System dynamics models have been widely used, especially with respect to the bullwhip-effect [8] and to model environmental and network related risk issues in inventory and logistics planning [9]. Risk management focus has long been given to the field of finance, with many management science tools to aid investors and insurers. Choi [5] generalize Wu and Olson's ERM work and methodology and term it as "W-O ERM Model", where it is unique to categorize five types of risk property: risk uncertainty, risk dynamics, risk interconnection, risk conflict and risk dependence.

We will briefly note some recent management science models applied to three critical risk management fields: finance, supply chain management, and social issues such as environmental and health analysis. This is motivated by the European focus in recent times on the triple bottom line of profit, service, and social responsibility. Models will be further classified by modeling type, with primary categories being optimization (either analytic analysis of mathematical programming), simulation, multicriteria analysis, and data mining.

\subsection{Financial Risk Modeling}

The financial field is rich in applying management science tools. Some recent examples include conditional value-at-risk modeling [10], where fat-tail distributions of financial asset returns was modeled and tested on 10 S\&P 500 stocks. Another financial model of supply chain risk was a 
decision support system for fleet replacement capitalization which used comparison of valueatrisk of different types of vehicles [11]. Modeling financial decisions through risk scoring has been applied. Ho et al. [12] compared data envelopment analysis with traditional return on equity measures in risk scoring of over two dozen US publicly traded firms. Zhang et al. [13] used evolutionary optimization models of credit decision making. Portfolio selection has been modeled through entropy models [14] combining random and fuzzy uncertainties, focusing on the tradeoff frontier between return and risk. Thus it is obvious that emerging modeling techniques are widely applied to financial risk.

\subsection{Supply Chain Risk Modeling}

Other modeling approaches have been applied to the context of supply chain management. Hsieh gave an analytic model related to demand switching in supply chains [15]. Ebrahim Najid et al. provided a mixed-integer programming optimization model for supply chain contingency planning [16]. Tang et al. applied a fuzzy genetic algorithm approach to evaluate logistics strategies to lower supply chain risks [17]. Bogataj and Bogataj used parametric linear programming based on net present value to estimate supply chain vulnerability [18]. Goh et al. applied a stochastic bi-criterion algorithm to analyze a multi-stage global network problem with objectives of profit maximization and risk minimization [19]. Many studies applied analytic hierarchy process, to include recent studies such as assessment of an offshoring decision [20], the similar decision to select suppliers [21], overall supply chain risk evaluation [22], and inbound supply risk evaluation [23]. Blackhurst et al. presented a study considering multiple objectives for supplier risk assessment utilizing a generic multiple criteria analysis similar to the simple multiattribute rating theory (SMART) method [24]. Heckmann et al. provided a review of supply chain risk modeling [25]. While financial risk modeling has been around centuries longer than supply chain risk modeling, it is obvious that a great deal of research has recently been applied to supply chain risk analysis.

\subsection{Social Responsibility and Risk}

Social consciousness is realized as important in this era of global trade and global warming. Many management science approaches have been presented for various decisions in this domain. Cruz has presented a framework of global supply chain networks capable of considering tradeoffs in profit maximization, risk, and emissions of pollutants [26]. This approach has been extended to the supply chain decision of trading partner selection [27]. Practically every management science modeling approach has been used in the area of social responsibility. Wang and Huang [28] applied an analytic model to water allocation. Optimization models have been widely applied, to include analysis of robust investment in petroleum markets [29] and electricity markets $[30,31]$. Stochastic programming has been applied incorporating both value-at-risk and conditional value-at-risk concepts in pipeline management [32]. Bivariate interval linear programming has been used to analyze environmental decision making in general [33]. Multicriteria model examples include models to classify pipeline risk [34]. Data mining analyses include application of neural network modeling and decision trees to management of occupational injury risk [35]. 


\section{Examples of Management Science Approaches}

As noted above, we view a spectrum of management science modeling, ranging from analytic models intended to identify optimal decisions under usually rather rigid assumptions, mathematical programming to optimize interacting systems, and simulation modeling enabling numerical analysis of uncertainty. This spectrum allows various power in conclusions traded off against required assumptions. There also has been a great deal of interest in the past few decades in multicriteria analysis of tradeoffs, important both in the financial context of trading off risk and return, as well as in the more general analysis of complex systems with many conflicting objectives. The past few decades have also seen tremendous growth in data mining as a tool to deal with the massive amounts of data generated by ever-changing technology. All of these modeling types have been applied to risk modeling.

\subsection{Optimization Modeling Examples}

We reviewed some of the many financial risk modeling examples in section 2.1, most of which tend to be of the analytic optimization type. Here we will focus on optimization modeling of risk in supply chains.

A number of analytic modeling papers have been applied. Hult et al. provided one example of real options theory applied to supply chain risk analysis [36]. Demarzo et al. [37] analytical modeled dynamic incentive contracting in analysis of optimal contracting policies. Nejad and Kuzgunkaya [38] applied analytic modeling to risk management in a supply chain context seeking robust design.

Mathematical programming has often been used to support risk management. In the supply chain field, Sawik [39] used mixed integer programming to model a dynamic supply chain portfolio problem of supplier selection and order allocation. Integer linear programming was used by Micheli et al. [40] for supply chain management under risk, as did Nejad et al [41]. Käki et al. [42] used stochastic programming for supply chain planning.

\subsection{Simulation Modeling Examples}

Simulation modeling allows any assumptions, pretty much the opposite of optimization modeling. However, optimization modeling enables proving things, at least for the domain covered by what the model assumes, while simulation can't. Thus there is a fundamental tradeoff.

An example of simulation modeling of a financial decision within supply chains was provided by Hua et al. [43], who analyzed operational interactions among supply chain members facing bankruptcy propagation. Hong and Lee [44] used Monte Carlo simulation of a supplier selection decision in a spot market, enabling allocation of orders to improve profitability and robustness. DEA value-at-risk modeling has been proposed as a tool to aid in vendor selection through a Monte Carlo simulation model [45]. There have been a number of agent-based simulation models within supply chain domains enabling a means of addressing complexity [46, 
47]. Wakolbinger and Cruz [48] gave an overview framework of supply chain network information and risk sharing.

\subsection{Multicriteria Modeling}

There are many multiple criteria methods. Some focus on selection from a given set of alternatives. There are a plethora of methods of this type. One in analytic hierarchy process, which was used in [50] to select appropriate suppliers supported by genetic algorithms. Another is PROMETHEE, an outranking method, applied in [51] in a decision support system to rank banks while considering multiple factors. ELECTRE is a closely related outranking method, applied in [51] for evaluating credit institutions for probability of default. Multicriteria mathematical programming combines consideration of multiple objectives with optimization. $\mathrm{Yu}$ and Goh [52] presented such a model to evaluate supply chain visibility and risk.

\subsection{Data Mining}

Data mining has emerged as a very active field applied to practically every field of science. There is a wide variety of data mining tools available, and a number of different techniques in an evolving area of research. A classical data mining application is credit approval classification. Chaudhuri [53] gave a current application in this field using fuzzy support vector machines. Wu et al. [54] applied decision trees, neural networks and logistic regression to accounts receivable risk analysis. Text mining deals with words rather than numbers. Groth and Muntermann [55] applied text mining to the financial services industry. Another emerging field is process mining, applied to compliance checking [56] and enterprise risk management in general [57] in recent studies.

\section{Contents of the Special Issue}

This issue begins with a literature review of climate policy modeling. Wei [58] used keyword analysis to identify the following topics in climate policy modeling:

1. Integrated assessment of climate policies,

2. Climate change uncertainty,

3. Temporal and spatial equity,

4. Technological change endogeneity,

5. Abatement mechanisms for greenhouse gases, and

6. Climate policy enterprise risk.

Three analytic modeling papers are included. Qi [59] modeled supply chain risk mitigation considering expedited shipping, demonstrating how the optimal mitigation strategy is affected. Luo [60] applied orthogonal GARCH, Markov switching, and exponentially weighted moving average models to hedge funds, and used sensitivity analysis to identify the impact of different parameter assumptions. Mersifonluoglu [61] analytically modeled supply chain portfolio procurement decisions, comparing forward contracts, option contracts, and spot purchases. Risk 
neutral and risk averse objectives were considered, and optimal properties developed under assumption of normality.

Simulation models also appear. These are of three different types. Pinior [62] applied traditional Monte Carlo simulation to dairy contamination, which identified the most vulnerable milk producers to whom control measures would be the most effective. Spinler [63] gave a system dynamics model to examine operational risk impact within supply chain networks. Shen [64] used human subjects in a behavioral simulation of fashion industry practitioners. Huang[65] consider Dual sourcing and backup production as two operational strategies for firms to mitigate supply risk.

\section{Conclusions}

Overall, this special issue includes a gamut of modeling variety of enterprise risk management. Both optimization and simulation appear. The editors of this special issue have been involved in writing a number of recent books on enterprise risk management including [2,3]. We view risk management to be an evolving field, based on financial enterprise risk management, but expanding into risk management of supply chains and analysis of social issues. Management science modeling tools of every kind have been applied, to include analytic modeling to identify optimal decisions, mathematical programming optimization, simulation modeling to reflect inherent risk, multicriteria models reflecting tradeoffs in today's world, and data mining to take advantage of the widespread growth in data. The papers in this special issue demonstrate the variety of modeling tools available to support enterprise risk management.

\section{Acknowledgments}

This work is partially supported by NFSC grant (Grant \# 71471055), the 100-Talents plan Program at Chinese Academy of Sciences, and Chinese Academy of Sciences Visiting Professorship for Senior International Scientists (Grant No. 2013T2J0054).

\section{References}

[1] Perrow C. Normal Accidents: Living with High-risk technologies. Princeton, NJ: Princeton University Press. 1999, original 1984.

[2] Wu DD, Olson DL. Enterprise Risk Management in Finance. Basingstoke, Hampshire: Palgrave Macmillan 2015.

[3] Olson DL, Wu DD. Enterprise Risk Management Models. Heidelberg: Springer, 2010.

[4] Wang S, Huang GH. An integrated approach for water resources decision making under interactive and compound uncertainties. Omega 2014, 44, 32-90. 
[5] Choi Y, Ye X, Zhao L and Luo C. Optimizing enterprise risk management: a literature review and critical analysis of the work of $\mathrm{Wu}$ and Olson. Annals of Operations Research, 2015, DOI 10.1007/s10479-015-1789-5.

[6] Sun Y, Apley DW, Staum J. Efficient nested simulation for estimating the variance of a conditional expectation. Operations Research 2011, 59(4), 998-1007.

[7] Wu D, Olson DL. Supply chain risk, simulation, and vendor selection. International Journal of Production Economics 2008, 114(2), 646-655.

[8] Towill DR, Disney SM. Managing bullwhip-induced risks in supply chains. International Journal of Risk Assessment \& Management 2008, 10(3), 238-262.

[9] Peng M, Peng Y, Chen H. Post-seismic supply chain risk management: A system dynamics disruption analysis approach for inventory and logistics planning. Computers \& Operations Research 2014, 42, 14-24.

[10] Zhao S, Lu Q, Han L, Liu Y, Hu F. A mean-CVaR-skewness portfolio optimization model based on asymmetric Laplace distribution. Annals of Operations Research 2015, 226(1), 727-739.

[11] Ansaripoor AH, Oliveira FS, Liret A. A risk management system for sustainable fleet replacement. European Journal of Operational Research 2014, 237(2), 701-712.

[12] Ho C-T, Wu DD, Olson DL. A risk scoring model and application to measuring internet stock performance. International Journal of Information Technology and Decision Making 2009, 8(1), 133-149.

[13] Zhang J, Avasarala V, Subbu R. Evolutionary optimization of transition probability matrices for credit decision-making. European Journal of Operational Research 2010, 200(2), 557-567.

[14] Xu J, Zhou X, Wu DD. Portfolio selection using $\lambda$ mean and hybrid entropy. Annals of Operations Research 2011, 185(1), 213-229.

[15] Hsieh Y-J. Demand switching criteria for multiple products: An inventory cost analysis. Omega 2011, 39(2), 130-137.

[16] Ebrahim Nejad A., Niroomand I, Kuzgunkaya O. Responsive contingency planning in supply risk management by considering congestion effects. Omega 2014, 48, 19-35.

[17] Tang CXH, Lau HCW, Ho GTS. A conceptual fuzzy-genetic algorithm framework for assessing the potential risks in supply chain management. International Journal of Risk Assessment \& Management 2008, 10(3), 263-271.

[18] Bogatai D., Bogatai M. Measuring the supply chain risk and vulnerability in frequency space. International Journal of Production Economics 2007, 108(1/2), 291-301.

[19] Goh M., Lim, JYS, Meng F. A stochastic model for risk management in global supply chain networks. European Journal of Production Economics 2007, 182(1), 164-173. 
[20] Schoenherr T, Rao Tummala VM, Harrison TP. Assessing supply chain risks with the analytic hierarchy process: Providing decision support for the offshoring decision by a US manufacturing company. Journal of Purchasing \& Supply Chain Management 2008, 14, 100-111.

[21] Kull TJ, Talluri S. A supply risk reduction model using integrated multicriteria decision making. IEEE Transactions on Engineering Management 2008, 55(3), 409-419.

[22] Gaudenzi B, Borghesi A. Managing risks in supply chain using the AHP method. The Interantional Journal of Logistics Management 2006, 17(1), 114-136.

[23] Wu T, Blackhurst J, Chidambaram V. A model for inbound supply risk analysis. Computers in Industry 2006, 57, 350-365.

[24] Blackhurst JV, Scheibe KP, Johnson DJ. Supplier risk assessment and monitoring for the automotive industry. International Journal of Physical Distribution \& Logistics Management 2008, 38(2), 143-165.

[25] Heckmann I, Comes T, Nickel S. A critical review on supply chain risk - Definition, measure and modeling. Omega 2015, 52, 119-132.

[26] Cruz JM. Modeling the relationship of globalized supply chains and corporate social responsibility. Journal of Cleaner Production 2013, 56, 73-85.

[27] Cruz JM. Mitigating global supply chain risks through corporate social responsibility. International Journal of Production Research 2013, 51(13), 3995-4010.

[28] Wang S, Huang GH. An integrated approach for water resources decision making under interactive and compound uncertainties. Omega 2014, 44, 32-40.

[29] Gülpinar N, Canakoglu E, Pachamanova D. Robust investment decisions under supply disruption in petroleum markets. Computers \& Operations Research 2014, 44, 75-91.

[30] Rocha P, Kuhn D. Multistage stochastic portfolio optimization in deregulated electricity markets using linear decision rules. European Journal of Operational Research 2012, 216(2), 397-408.

[31] Yao S, Kwon RH, Scott Rogers J, Wu D. Financial and operational decisions in the electricity sector: Contract portfolio optimization with the conditional value-at-risk criterion. International Journal of Production Economics 2011, 134(1), 67-77.

[32] Colvin M, Maravelias CT. R\&D pipeline management: Task interdependencies and risk management. European Journal of Operational Research 2011, 215(3), 616-628.

[33] He L, Huang GH, Lu H. Bivariate interval semi-infinite programming with an application to environmental decision-making analysis. European Journal of Operational Research 2011, 211(3), 452-465. 
[34] Brito AJ, de Almeida AT, Mota CMM. A multicriteria model for risk sorting of natural gas pipelines based on ELECTRE TRI integrating utility theory. European Journal of Operational Research 2010, 200(3), 812-821.

[35] Bevilacqua M, Ciarapica FE, Giacchetta G. Data mining for occupational injury risk: A case study. International Journal of Reliability, Quality \& Safety Engineering 2010, 17(4), 351-380.

[36] Hult GTM, Craighead C., Ketchen DJ Jr. Risk uncertainty and supply chain decisions: A real options perspective. Decision Sciences 2010, 41(3), 435-458.

[37] Demarzo PM, Fishman MJ, He Z, Wang N. Dynamic agency and the q theory of investment. Journal of Finance 2012, 67(6), 2295-2340.

[38] Nejad AE, Kuzgunkaya O. On the value of response time characteristics in robust design of supply flow. Journal of Manufacturing Technology Management 2015, 26(2), 213-230.

[39] Sawik T. Selection of a dynamic supply portfolio in make-to-order environment with risks. Computers \& Operations Research 2011, 38(4), 782-796.

[40] Micheli GJL, Mogre R, Perego A. How to choose mitigation measures for supply chain risks. International Journal of Production Research 2014, 52(1), 117-129.

[41] Kaki A, Salo A, Talluri S. Scenario-based modeling of interdependent demand and supply uncertainties. IEEE Transactions on Engineering Management 2014, 61(1), 101-113.

[42] Nejad EA, Niroomand I, Kuzgunkaya O. Responsive contingency planning in supply risk management by considering congestion effects. Omega 2014, 48, 19-35.

[43] Hua Z, Sun Y, Xu X. Operational causes of bankruptcy propagation in supply chain. Decision Support Systems 2011, 51(3), 671-681.

[44] Hong Z, Lee CKM. A decision support system for procurement risk management in the presence of spot market. Decision Support Systems 2013, 55(1), 67-78.

[45] Wu DD, Olson D. Enterprise risk management: A DEA VaR approach in vendor selection. International Journal of Production Research 2010, 48(16), 4919-4932.

[46] Giannakis M, Louis M. A multi-agent based framework for supply chain risk management. Journal of Purchasing \& Supply Management 2011, 17(1), 23-31.

[47] Wu T, Huang S, Blackhurst J, Zhang X, Wang S. Supply chain risk management: An agent-based simulation to study the impact of retail stockouts. IEEE Transactions on Engineering Management 2013, 60(4), 676-686.

[48] Wakolbinger T, Cruz JM. Supply chain disruption risk management through strategic information acquisition and sharing and risk-sharing contracts. International Journal of Production Research 2011, 49(13), 4063-4084. 
[49] Cao Y, Luo X, Kwong CK, Tang J. Supplier pre-selection for platform-based products: A multi-objective approach. International Journal of Production Research 2014, 52(1), 1-19.

[50] Doumpos M, Zopounidis C. A multicriteria decision support system for bank rating. Decision Support Systems 2010, 50(1), 55-63.

[51] Doumpos M, Zopounidis C. A multicriteria outranking modeling approach for credit rating. Decision Sciences 2011, 42(3), 721-742.

[52] Yu M-C, Goh M. A multi-objective approach to supply chain visibility and risk. European Journal of Operational Research 2014, 233(1), 125-130.

[53] Chaudhuri A. Modified fuzzy support vector machine for credit approval classification. AI Communications 2014, 27(2), 189-211.

[54] Wu DD, Olson DL, Luo C. A decision support approach for accounts receivable risk management. IEEE Transactions on Systems, Man \& Cybernetics 2014, 44(12), 16241632.

[55] Groth SS, Muntermann J. An intraday market risk management approach based on textual analysis. Decision Support Systems 2011, 50(4), 680-691.

[56] Caron F, Vanthienen J, Baesens B. Comprehensive rule-based compliance checking and risk management with process mining. Decision Support Systems 2013, 54(3), 1357-1369.

[57] Caron F, Vanthienen J, Baesens B. A comprehensive investigation of the applicability of process mining techniques for enterprise risk management. Computers in Industry 2013, 64(4), 464-475.

[58] Wei Y, Mi Z and Huang Z. Climate policy modeling: An online SCI-E and SSCI based literature review. Omega 2015. doi:10.1016/j.omega.2014.10.011

[59] Qi L and Lee K. Supply chain risk mitigations with expedited shipping. Omega 2015. doi:10.1016/j.omega.2014.07.010

[60] Luo A, Seco L and Wu Y. Portfolio optimization in hedge funds by OGARCH and Markov switching model. Omega 2015.

[61] Merzifonluoglu Y. Risk averse supply portfolio selection with supply, demand and spot market volatility. Omega 2015. doi:10.1016/j.omega.2015.03.006

[62] Pinior B, Conrathsa F J, Petersenb B, Selhorstd T. Decision support for risk manahers in the case of deliberate food contamination: The dairy industry as an example. Omega 2015. doi:10.1016/j.omega.2014.09.011

[63] Guertler B, Spinler S. When does operational risk cause supply chain enterprises to tip? A simulation of intra-organizational dynamics. Omega 2015. Doi:

10.1016/j.omega.2015.03.005 
[64] Chow P, Wang Y, Choi T Shen B. An experimental study on the effects of minimum profit share on supply chains with markdown contract: Risk and profit analysis. Omega 2015. Doi:10.1016/j.omega.2013.11.007

[65] Huang $\mathrm{H}$ and $\mathrm{Xu}$ H. Dual Sourcing and Backup Production: Coexistence versus Exclusivity. Omega 2015. 